\title{
Macroformas do Relevo da América do Sul
}

\section{Relief Macroforms of South America}

\author{
Jurandyr Luciano Sanches Ross* $\varangle$ (D), Marisa de Souto Matos Fierz $₫$ (D), \\ Pablo Luíz Maia Nepomuceno $₫$ (iD, Marcos Antonio de Melo $\varangle$ (iD \\ Departamento de Geografia, Faculdade de Filosofia, Letras e Ciências Humanas, \\ Universidade de São Paulo - São Paulo, Brasil. \\ E-mails:msmattos@usp.br (MSMF); pablonepomuceno@gmail.com (PLMN); \\ marcosamelo@yahoo.com.br (MAM). \\ *E-mail para correspondência: juraross@usp.br (JLSR).
}

Recebido (Received): 31/05/2019 Aceito (Accepted): 17/10/2019.

\begin{abstract}
Resumo: O relevo sulamericano representado no Mapa das Macroformas do Relevo da America do Sul pode ser interpretado a partir dos processos geológicos e geomorfológicos pós-gondwânicos, aos quais estão relacionadas, a abertura do Oceano Atlântico e a formação da Cadeia Orogenética dos Andes. A tectônica por meio da epirogênese meso-cenozóica, afetou o centro-leste do continente e desencadeou, em conjunto com as atividades climáticas, os processos morfogenéticos denudacionais e estabeleceram a compartimentação do relevo, a qual está aqui representada pelas macroformas também denominadas de Morfoestruturas. Essas macroformas associam-se também às megaestruturas dos Crátons, Cinturões Orogenéticos e Bacias Sedimentares herdadas do Gondwana, produzidas pelas fases erosivas pré e pósCretáceo. No oeste do continente com a ocorrência da orogenia e no centro-leste a epirogenia e consequentes arqueamentos e falhamentos criaram desníveis de antigas superfícies de erosão, acompanhadas de processos erosivos e deposicionais mais recentes datados do Terciário e do Quaternário. A esses processos associam-se os períodos glaciais e interglaciais, os quais no mundo tropical se manifestaram por meio dos climas secos e pouco mais frios seguidos de períodos quentes e úmidos alternando-se ao longo do Pleistoceno/Holoceno. Todas as formas interpretadas e analisadas nesta pesquisa são resultantes de processos geomorfológicos exógenos atuantes sobre os materiais que sustentam o relevo da América do Sul.
\end{abstract}

Palavras-chave: Relevo; Mapa das Macroformas; América do Sul; Tectônica; Orogênese; Epirogênese.

\begin{abstract}
The South American relief represented by this Map of Macroforms can be understood from the geological and geomorphological processes post gondwanico with wich they are related by the opening of the Atlantic Ocean and the formation of the Andean Orogenic Chain. The tectonics through the mesocenozoic epirogenesis affected the eastern central part of the continent and started the erosion processes and established the division of the relief. Macroforms are associated with the mega-structures of the Cratons, Orogenic Belts and Sedimentary Basins inherited from Gondwana, produced by the pre- and postCretaceous erosive phases. In the west of the continent the orogeny and in the center-east epirogenia with archings and faults that created uneven of old surfaces of erosion, accompanied by erosive and depositional processes Tertiary and Quaternary, associated to the glacial and interglacial periods that in the tropical world were manifested through the climates dry and slightly colder followed by hot and humid that alternated along the Pleistocene / Holocene. Thus, all the forms interpreted and analyzed in this research are due to exogenous processes on the materials that sustain the relief of South America.
\end{abstract}

Keywords: Relief; Map of Macroforms; South America; Tectonics; Orogenesis; Epirogenesis. 


\section{Introdução}

\subsection{Representação do Relevo para a América do Sul}

$\mathrm{O}$ volume de informações geológicas e geomorfológicas, produzidas por inúmeros autores, somadas às consultas ao Mapa Geológico da América do Sul organizado e sintetizado pela Companhia de Pesquisa de Recursos Minerais (CPRM), o uso sistemático das imagens de satélite disponíveis no Google Earth e de radar SRTM (Shuttle Radar Topography Mission) produzidas pela Agência Espacial norte americana (NASA), acrescido de algumas viagens exploratórias de campo, foram fundamentais para construir o Mapa das Macroformas do Relevo da América do Sul. A publicação de Ross (2016) na Revista Brasileira de Geografia, volume 26 denominado "Relevo Brasileiro no Contexto da América do Sul", onde pela primeira vez se propôs classificação do relevo para todo o continente, apresentando-o por meio de uma figura muito reduzida, nos encorajou a gerar um produto cartográfico mais completo, com a delimitação mais refinada dos limites das unidades do relevo ali representadas, bem como um texto mais sucinto e preciso das unidades morfoestruturais e morfoesculturais da América do Sul. Para isto, seguiu-se a proposta metodológica embasada nos conceitos de morfoestrutura e morfoescultura, preconizados pelos geomorfólogos russosoviéticos I. Guerasimov e J.A. Mecerjakov, conforme Mecerjakov (1968) e acrescentados pela proposição taxonômica de Ross (1992).

A primeira classificação geral do relevo da América do Sul foi elaborada por George Berry, publicada no livro Geomorphology de O. D. Von Engel, em 1942, pela editora The Macmilllan Company, New York, USA, estando reproduzida no artigo de Ross (2016) supracitado.Foi a primeira proposta para se entender a distribuição e as características do relevo sulamericano.

$\mathrm{Na}$ atualidade, quando se dispõe de enorme quantidade de publicações, sobretudo da geologia e geomorfologia do continente como um todo, associado às tecnologias disponíveis, foi possível apresentar uma nova versão sobre o tema, com a preocupação de tornar mais clara as relações existentes entre os arranjos estruturais e morfológicos de todo o continente. Os nomes destas também passaram por alguns ajustes de denominações em função da escala regional que representam.

\section{O Relevo Regional Sul-americano}

O relevo da América do Sul está contextualizado na macro-compartimentação e geodinâmica do continente, que por sua vez depende da geotectônica global ou seja no entendimento da teoria da Tectônica de Placas. Os fatos geotectônicos, tanto do passado como do presente, são interpretados através do arcabouço global do planeta, e os fatos locais e regionais só podem ser entendidos também nesse contexto. As terras emersas atuais do planeta se configuram em macroestruturas geológicas muito antigas do Pré-Cambriano médio e inferior (Arqueozóico) através dos Crátons,. Agregados a essas megaestruturas desenvolveram-se outros arranjos estruturais com características de faixas ou cinturões de dobramentos datados do PréCambriano Superior (Proterozóico) aqui denominados de Cinturões Orogenéticos Antigos. Sobre essas estruturas antigas os processos erosivos e deposicionais geraram as grandes Bacias Sedimentares Paleomesozoicas com diferentes condições climáticas, tectônicas e marinhas. Estas bacias formaram-se dominantemente sobre e entre crátons e cinturões orogenéticos antigos. Esse complexo conjunto de megaestruturas que fazem parte da litosfera do planeta, estão assentadas sobre o manto, que é composto por material viscoso, sobreposta pelo mais denso e quente. A menor densidade das rochas que compõem as terras emersas, combinada com os movimentos crustais decorrentes das forças endógenas, possibilita uma vigorosa dinâmica da crosta litosférica que ao longo dos tempos geológicos mais recentes agregaram novas formações rochosas, novos arranjos estruturais e consequentemente macro formas do relevo, que também se submetem aos longos processos erosivos e deposicionais, sobretudo, do período Cretáceo ao Cenozóico (Terciário e Quaternário). Estas novas megaestruturas e macroformas do relevo estão representadas por extensa cadeia orogenéticas (Andes), amplas depressões interiores e planícies como da Depressão Central Sulamericana e por Planaltos, Serras e Depressões, estas últimas produzidas por longos períodos erosivos ao longo do Cenozóico.

As formas e os processos responsáveis pela formação do relevo sul americano, estão contextualizados na perspectiva da tectônica global, onde os arranjos estruturais de hoje não são os mesmos de tempos geológicos passados, mas se assemelham. 


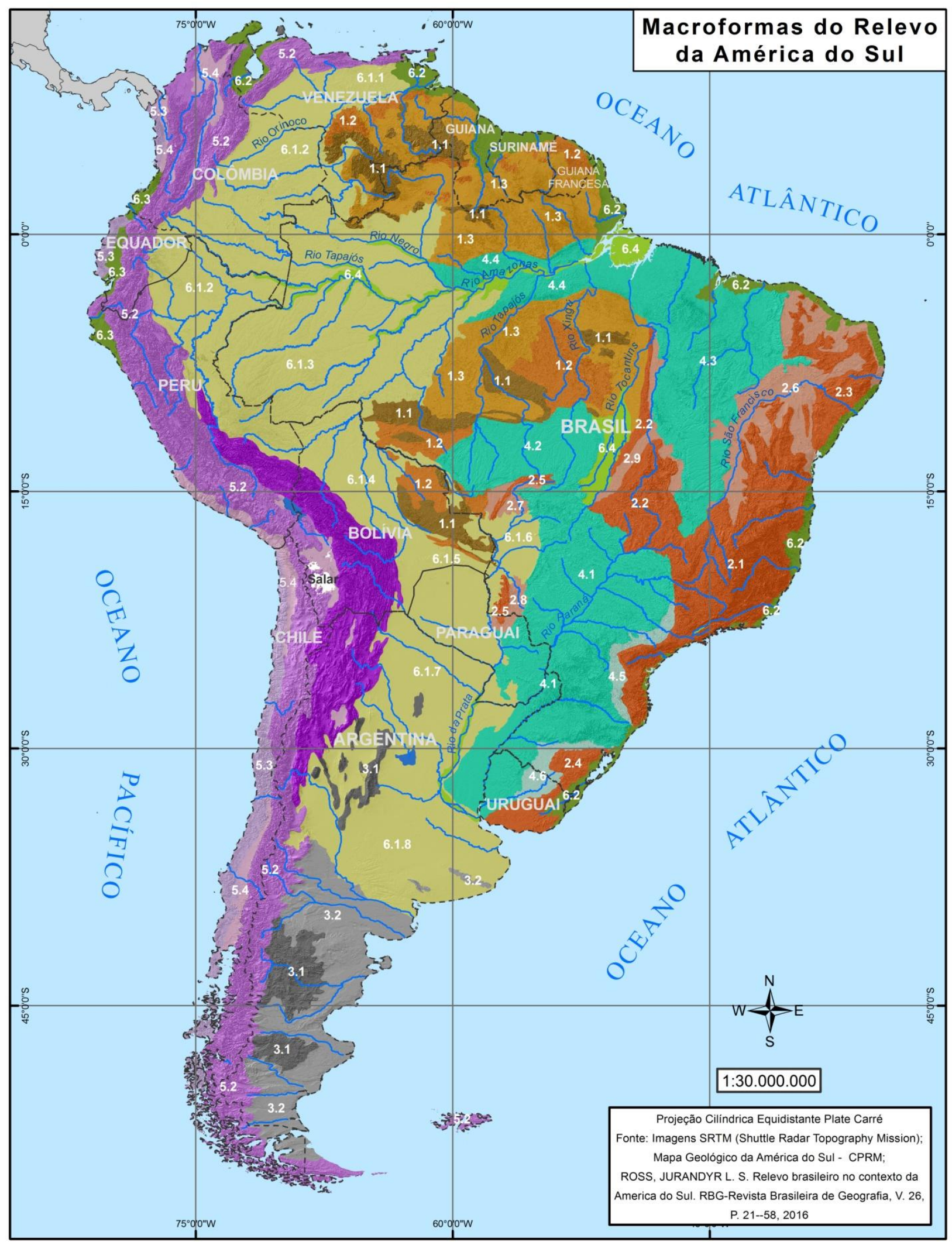

Figura 1: Mapa das Macroformas do Relevo da América do Sul. Fonte: Elaboração própria.

A Figura 2 ilustra a divisão dos primeiros e segundos táxons: as morfoestruturas e morfoesculturas conforme representados no mapa (Figura 1): 
1-Morfoestrutura do Cráton Amazônico:

-Morfoesculturas:

1.1-Planaltos Residuais em Cobertura Sedimentar de Plataforma-Norte e Sul Amazônicos

1.2-Planaltos em Estruturas Ígneas e Metamórficas-Norte e Sul Amazônicas

1.3-Depressões Marginais e Interplanálticas - Norte e Sul Amazônicas

2-Morfoestrutura dos Cinturões Orogenéticos do Pré-Cambriano:

-Morfoesculturas:

2.1-Planaltos e Serras do Atlântico Leste-Sudeste

2.2-Planaltos e Serras de Goiás-Minas

2.3-Planaltos do Nordeste Oriental e Sertanejo

2.4-Planalto Uruguaio-sul-rio-grandense

2.5-Planaltos e Serras do Alto Paraguai/Bodoquenal

2.6-Depressões Sertaneja e do São Francisco

2.7-Depressões Cuiabana e do Alto Paraguai

2.8-Depressões do Miranda-Bodoquena

2.9-Depressões do Tocantins

3-Morfoestrutura da Plataforma da Patagônia:

-Morfoesculturas:

3.1-Planaltos em Estruturas Vulcano-sedimentares

3.2-Planaltos em Coberturas Sedimentares Meso-cenozóicas

4-Morfoestruturas em Bacias Sedimentares Paleo-mesozoicas:

-Morfoesculturas:

4.1-Planaltos e Chapadas da Bacia do Paraná

4.2-Planaltos e Chapadas da Bacia do Parnaíba

4.3-Planaltos e Chapadas da Bacia do Parecis

4.4-Planaltos e Tabuleiros da Bacia da Amazônia Oriental

4 4.5-Depressão Periférica da Borda Leste da Bacia do Paraná

$\square$ 4.6-Depressão Periférica Central Gaúcha-Uruguaia

5-Morfoestruturas dos Cinturões Orogenéticos Meso-cenozóicos:

-Morfoesculturas:

ए 5.1-Cordilheira dos Andes Oriental

5.2-Cordilheira dos Andes Centro-Ocidental

$\square$ 5.3-Cordilheira dos Andes Costeira

$\square$ 5.4-Vales Sinclinais-Patamares Estruturais Amplos e Altiplanos

6 - Morfoestruturas das Bacias Sedimentares Cenozóicas:

-Morfoesculturas:

$\square$ 6.1-Depressão Central Sul-americana

$\square$ 6.1.1-Tabuleiros e Colinas da Bacia do Orinoco

6.1.2-Tabuleiros e Colinas da Bacia do Solimões

$\square$ 6.1.3-Tabuleiros e Colinas do Alto Paraguai

6.1.4-Planícies e Pantanais da Bacia do Orinoco

6.1.5-Planícies e Pantanais das bacias Beni-Mamoré (Chaco)

6.1.6-Planícies e Pantanais das Bacias Paraguai-Paraná (Chaco)

6.1.7-Planícies e Colinas das Bacias Paraguai-Paraná-Prata

6.1.8-Planícies e Campos de Dunas Fixas das Bacias do Salado-Colorado

6.2-Tabuleiros Costeiros e Planícies Flúvio-Marinhas do Atlântico

6.3-Terracos e Planícies Costeiras do Pacífico

6.4-Planícies Fluviais Interiores

Figura 2: Legenda ilustrativa da divisão dos primeiros e segundos táxons das macroformas do relevo da América do Sul. 
As terras emersas da América do Sul fazem parte de algo maior, a Placa Litosférica sul-americana que envolve também superfícies submersas. O relevo do continente sul-americano tem na borda oeste a Cadeia Orogênica dos Andes, cuja formação se inicia no Jura-Cretáceo e estende-se ao Cenozóico. No interior do continente, acompanha a cordilheira Andina de norte a sul, uma faixa de terras baixas, a que denominamos de Depressão Central Sulamericana, constituída por planícies, pantanais e depressões constituídos por sedimentos Cenozóicos. No centro-leste e norte do continente as estruturas e formações litológicas são antigas e remontam ao Pré-cambriano estando parcialmente cobertas por extensas bacias sedimentares Paleomesozóicas onde estão grandes formas de relevo como planaltos e serras intercalados por superfícies rebaixadas por erosão correspondendo às depressões periféricas e interplanálticas.

As plataformas ou crátons, são morfoestruturas que correspondem aos terrenos mais antigos e rebaixados por centenas de milhões de anos por atividades erosivas, compõem-se por uma grande complexidade litológica e estrutural, com predomínio de rochas metamórficas muito antigas do Pré-Cambriano Médio a Inferior (Arqueozóico), bem como rochas metamórficas e intrusivas antigas do Pré-Cambriano Médio a Superior (Proterozóico). Também ocorrem rochas sedimentares datadas do mesmo Proterozóico, que recobrem residualmente pequenas áreas dos terrenos dos crátons ou plataformas. Essas áreas de plataformas antigas correspondem partes do cráton Amazônico, do São Francisco, Uruguaio-sul-rio-grandense e Patagônia, tendo maior expressividade e continuidade territorial o Cráton Amazônico (Ross, 2016).

As morfoestruturas representadas pelos cinturões orogenéticos correspondem às extensas faixas de estruturas dobradas e metamorfizadas, correspondendo as diversas fases ao longo do Pré-Cambriano Superior (Proterozóico). Esses cinturões, conforme ressalta Almeida (1967), representam faixas de sutura entre crátons e consolidam os terrenos do Pré-Cambriano, sobretudo em território brasileiro. Estão representados pelas faixas de dobramentos do Atlântico, de Brasília e Paraguai-Araguaia. Essas três antigas cadeias montanhosas foram geradas pela dinâmica crustal do Proterozóico. Constituíam bacias sedimentares de bordas de continentes que, por pressões dos deslocamentos crustais de grandes blocos estruturais, foram transformadas em cadeias orogenéticas longas, estreitas e elevadas. São decorrentes de processos de dobramentos, metamorfismos regionais, magmatismos com intrusões e vulcanismos, mas também passaram e continuam passando por desgastes erosivos dos últimos 550/600 milhões de anos (Fanerozóico), encontrando-se muito rebaixadas pelas várias fases denudacionais, mas ainda guardando aspecto montanhoso e serrano em grandes extensões (Ross, 1990).

As grandes bacias sedimentares paleo-mesozóicas, como a Amazônica Oriental, do Parnaíba, do Paraná e do Parecis compõem a terceira grande tipologia de morfoestruturas, que ocorrem na América do Sul. Os depósitos marinhos, glaciais, eólicos e continentais formaram as rochas sedimentares dessas três grandes bacias. Compõem os estratos sedimentares os arenitos de diferentes idades e granulações, intercalados por camadas de siltitos, argilitos, folhelhos, conglomerados e calcários, entre outros. Especificamente, na Bacia do Paraná ocorreu, no Jurássico, extensivo derrame de lavas vulcânicas predominantemente básicas (basaltos), que se acomodaram sobre as camadas sedimentares em planos pseudo-horizontais. A formação dessas grandes bacias sedimentares teve interrupção de sedimentação generalizada no fim do Mesozóico (Cretáceo). Os sedimentos dessas bacias resultam dos múltiplos processos erosivos dos cinturões orogenéticos e dos crátons, com muita variabilidade de condições climáticas, promovendo processos erosivos e deposicionais em condições de climas quentes e úmidos, desérticos e glaciais em ambientes continentais e marinhos.

As morfoestruturas dos cinturões orogenéticos recentes e das bacias sedimentares cenozóicas associam-se a origem da cordilheira andina e a formação da Depressão Central Sul americana, respectivamente as terras mais altas e as mais baixas do continente.

Os depósitos do Cenozóico relativos à Depressão Central Sul Americana, são encontrados mais extensivamente na parte ocidental da Bacia Amazônica (Solimões), nas Bacias do Orinoco, do ParaguaiParaná, mas também nos tabuleiros costeiros e planícies marinhas e fluviais nos litorais dos Oceanos Atlântico e Pacífico. Encontram-se também bacias sedimentares terciário-quaternárias nas faixas dos dobramentos do Atlântico e dos Andes em grábens ou rift valleys como em depressões de origem tectônica e em vales sinclinais alçados e anticlinais erodidos.

O desafio para entender a morfogênese e a morfocronologia do relevo da América do Sul como um todo, está sempre em se considerar em primeiro momento a tectônica antiga e os arranjos estruturais decorrentes dela, seguidos pelos processos denudacionais que ocorreram por centenas de milhões de anos atuando nos crátons (escudos e plataformas) e nos cinturões orogenéticos do pré-Cambriano. São determinantes na configuração da morfologia do continente as atividades da tectônica mais recentes, iniciadas no JuraCretáceo e estendidas por todo o Cenozóico, como os dobramentos, soerguimentos/arqueamentos, 
basculamentos, falhamentos, vulcanismo e distensões vinculadas a neotectônica, acompanhada simultaneamente pelos rebaixamentos e reafeiçoamentos erosivos.

A complexidade da análise na perspectiva morfogenética, precisa inexoravelmente contemplar os processos denudacionais ativados permanentemente pelas oscilações e mudanças climáticas ao longo do tempo geológico e do espaço geográfico. Climas frios, quentes, secos, úmidos e glaciais são agentes e indicadores de diferentes processos erosivos e deposicionais, que deixaram e continuam deixando suas marcas nas formas de acumulação e principalmente em seus correspondentes depósitos. Estes "mistérios" geomorfológicos têm seus "segredos científicos" registrados nos espessos e bastante profundos pacotes sedimentares que compõem os depósitos Terciário-Quaternários das morfoestruturas das bacias sedimentares cenozóicas.

A revisão do conhecimento geomorfológico do território brasileiro, apresentada por Ab’Saber (1998), é importante ponto de partida para entender a morfogênese do relevo brasileiro e nos permite remeter às interpretações correlativas para todo o continente sul-americano, tanto nos aspectos geotectônicos e estruturais antigos e recentes, como os esculturais com destaque para os atuantes no Terciário e no Quaternário. A contribuição de inúmeros outros pesquisadores, cujas análises e interpretações são parcialmente relatadas em Ross (2016), permitem estabelecer como objetivo, por meio de representação no mapa geomorfológico da America do Sul, um entendimento ainda que genérico sobre a morfogênese e morfocronologia das macroformas.

\section{Morfoestrutura da Plataforma ou do Cráton Amazônico.}

Referindo-se aos terrenos geologicamente mais antigos da América do Sul, com destaque para o Brasil e Venezuela, mais especificamente relacionados ao Cráton Amazônico, Ab’Saber (1972), BRASIL (19711985) e Ross (1990) registram que prevalece uma vasta superfície baixa com altitudes que oscilam entre 100 e $300 \mathrm{~m}$, esculpidas no embasamento cristalino mantido por rochas metamórficas do Pré-Cambriano Médio (1,8 a 2,5 bilhões de anos). Essa superfície é a dominante do Cráton Amazônico desde o sul do Estado de Mato Grosso até a Venezuela, Suriname e Guianas. Essa vasta superfície rebaixada por processos erosivos ao longo de centenas de milhões de anos é o que melhor caracteriza o Cráton Amazônico contemporâneo.

$\mathrm{Na}$ parte central, cortada pelo rio Amazonas está a cobertura paleo-mesozoica da bacia sedimentar Amazônica oriental, cujos desníveis entre os topos das bordas da bacia para a base da superfície, que está por volta dos 100m de altitude, é de 200 a 300m. Essa superfície Gondwânica de idade pré-Paleozoica, foi tratada por Ab'Saber como uma "superfície de eversão", em função da exumação que teria ocorrido ao longo do Terciário-Quaternário. No território brasileiro, essa superfície foi denominada por Ab’Saber, em 1972, como Depressão Marginal Norte e Sul Amazônica em face da presença no eixo Leste-Oeste da Bacia Sedimentar da Amazônia Oriental. Esse nível é muito pouco inclinado de sul para norte e também de norte para sul em relação ao eixo do rio Amazonas. As características morfológicas dessa superfície, tanto a norte como ao sul da bacia sedimentar amazônica, são dominantemente constituídas por colinas de topos convexos com vales encaixados e vertentes medianamente inclinadas.

Observa-se por toda essa superfície baixa e colinosa, relevos mais elevados, com altitudes entre 600 e 800m, a que denominamos de Planaltos Residuais Norte e Sul Amazônicos. Essas formas residuais em áreas restritas podem ultrapassar os 1.000 metros. São relevos mantidos por grande diversidade de litologias, como rochas ígneas da família dos granitos, com alguma presença de vulcânicas ácidas, como os riolitos, e coberturas residuais, compostas por arenitos silicificados. Também estão presentes relevos residuais esculpidos em estruturas dobradas do Pré-Cambriano Médio representadas por cristas assimétricas de quartzitos, heranças de fases orogenéticas mais antigas que, na evolução geológica, levaram à formação do Cráton. Há ainda relevos cujos topos são mantidos por formações ferríferas e de manganês muito resistentes à erosão, que constituem depósitos supergênicos do Pré-Cambriano e sustentam relevos residuais elevados, como ocorre com o complexo serrano de Carajás, no Pará, e de Urucum, em Mato Grosso do Sul.

Os arenitos silicificados, também extremamente resistentes ao desgaste erosivo sustentam os topos aplanados ou dissecados, mas com topos nivelados denominados de Planaltos com Coberturas Residuais de Plataforma Norte e Sul Amazônicos, como exemplo são as Serras da Providência e Pacaás Novos, em Rondônia, do Cachimbo, de Caiabis, de Apiacás, Santa Bárbara, Tapirapé e Cubencranquem, em Mato Grosso e Pará, e as Serras de Parima, Pacaraima, e Tumucumaque respectivamente nas divisas de Roraima/Venezuela, e Amapá/Suriname. Recobrem o cráton Amazônico de forma mais contínua a bacia sedimentar da Amazônia Oriental, com o eixo hidrográfico do rio Amazonas e a bacia sedimentar do Parecis, posicionada no divisor de águas dos rios que vertem para o Amazonas ao norte, e os rios tributários do Paraguai/Paraná, ao sul. Essas bacias têm o fecho da sedimentação nos arenitos do Cretáceo, com a diferença 
que as partes mais elevadas dos sedimentos do Cretáceo, na Bacia Amazônica, estão entre 350/400m, enquanto no Planalto dos Parecis, oscilam entre 400 a $800 \mathrm{~m}$.

\section{Morfoestrutura da Plataforma da Patagônia}

A Morfoestrutura da Plataforma da Patagônia também se apresenta preferencialmente como terras baixas, à semelhança do Cráton Amazônico, mas na perspectiva geomorfológica é bastante distinta. Essa plataforma com parte das rochas mais antigas datadas do Pré-Cambriano Superior é tida como parte residual do continente Gondwana. Sua configuração resulta do amalgamento de dois maciços cristalinos denominados de Somun Cura, ao norte, e Deseado, ao sul. Esses maciços se compõem de grande complexidade de rochas metamórficas intrusivas da família dos granitos, vulcânicas ácidas, como os riolitos e ignibritos associados ao vulcanismo do Jura-Triássico, os basaltos e sedimentos do Terciário inferior (Paleógeno).

Recobrem parcialmente essas litologias mais antigas, sedimentos do Cretáceo e Terciário, bem como estruturas horizontais dos derrames vulcânicos constituídos por basaltos, que sustentam relevos tabulares denominados de mesetas com bordas escarpadas, topos planos, recortados por vales de direção oeste-leste paralelos entre si, largos, de fundos preferencialmente planos e bordas escarpadas. Esses vales de dimensões desproporcionais ao volume de água que neles circula, tem gênese associada aos processos glaciais e áridos do Pleistoceno. Os setores dos maciços de Deseado e Somun Cura, com altitudes que atinge os $800 \mathrm{~m}$, são marcados por relevos em morros com morfologia irregular, vertentes abruptas, configurando uma intensa rugosidade e dessimetria topográfica.

No baixo Planalto da Patagônia, onde prevalecem as mesetas, as coberturas do Cretáceo e Terciário compostas por arenitos, tilitos, conglomerados, drumlins, calcáreos bem como os derrames de basalto, se mantêm mais extensivamente, indicando ao mesmo tempo em que embora essa plataforma esteja no contato da borda leste da Cordilheira Andina, os soerguimentos epirogenéticos foram mais modestos a leste e mais significantes a oeste. As altitudes decaem na direção do Atlântico variando entre 400/600m a oeste e menos de $100 \mathrm{~m}$ na zona costeira do Atlântico.

\section{Morfoestruturas dos Cinturões Orogenéticos Antigos}

Os cinturões orogenéticos antigos em território brasileiro datam do ciclo brasiliano, ou seja, entre 550 milhões a 1,5 bilhões de anos, sendo representados pelos cinturões do Attântico, Brasília e ParaguaiAraguaia. Ross (1991) ao tratar do relevo da Província Serrana de Mato Grosso que compõe parte dos Planaltos e Serras Residuais do Alto Paraguai, discute a diversidade genética dos níveis morfológicos ou topográficos dos relevos dessas faixas de dobramentos, que inclui as áreas serranas e as depressões circundantes como Depressão Cuiabana e do Alto Paraguai, pertencentes ao cinturão orogenético ParaguaiAraguaia. Apresenta a seguinte síntese morfogenética e cronológica:

I - "No Pré-Cretáceo as fases erosivas deixaram como testemunhos superfícies aplanadas e ou niveladas no topo da Província Serrana e no Planalto das Bacias do Rio Casca e Mutum" (ROSS 1991a, p.35). - No Cretáceo ocorre a sedimentação dos Grupos Parecis e Bauru que dão suporte às Chapadas dos Parecis e Guimarães, bem como o recobrimento em nítida discordância erosiva dos topos aplanados e preservados das anticlinais da Província Serrana.

II - Em publicação mais recente, Ross (2014) conclui que os processos esculturais ou denudacionais que ocorreram nessa região se deram simultaneamente aos arqueamentos/soerguimentos do chamado "Arco de São Vicente", ao longo do Cenozóico.

1- $\quad$ Soerguimento da Plataforma Brasileira, ou seja, a epirogênese que se manifesta a partir do JuraCretáceo, que promoveu a reativação de falhas antigas e o basculamento de blocos, gerando desnivelamentos na Província Serrana. - Do Terciário Médio ao Pleistoceno consolida-se a abertura das Depressões do Alto Paraguai, Cuiabana e Periférica do Arinos. - No Pleistoceno ocorreu a deposição dos sedimentos preferencialmente arenosos da Formação Pantanal sobre a superfície aplanada das Depressões do Alto Paraguai e Cuiabana;

IV-

No Pleistoceno mais recente e no Holoceno a continuação dos processos de sedimentação fluvial/lacustre em regimes de leques aluviais geram a Planície do Pantanal e ao mesmo tempo promovem dissecação das terras pouco mais altas do entorno, inclusive os próprios sedimentos da Formação Pantanal ao longo da Depressão do Alto Paraguai, drenada pelos rios Paraguai, Sepotuba e Pari.

2- $\quad$ Na faixa dos dobramentos Brasília ou Cinturão Orogenético de Brasília, Ross (2001) refere-se às morfologias e à gênese dos relevos do norte Goiano e Distrito Federal, e onde também inclui-se a Serra da 
Canastra em Minas Gerais, podendo-se resumir na seguinte sequência morfogenética e cronológica: 1) Os relevos montanhosos constituídos por serras, planaltos e depressões intermontanas, que configuram a geomorfologia da área, se encaixam perfeitamente na interpretação genérica de que a faixa de dobramentos que compõe este relevo é parte de um processo geotectônico do Pré-Cambriano Superior (Proterozóico) e, 2) Os processos erosivos, à semelhança do que ocorreu em outras áreas do atual território nacional, rebaixaram as montanhas que no passado possivelmente atingiriam altitudes próximas dos 3.000/4.000m.

3- Observam-se, contemporaneamente, os relevos montanhosos, esculpidos sobre as rochas que compunham "as raízes" dos dobramentos da antiga cordilheira. Vislumbra-se de forma genérica que as atuais Serras Dourada, da Mesa, das Traíras, Branca, Canastra e Chapadas dos Veadeiros e Brasília, são produtos residuais das diversas fases de rebaixamento erosivo dessa cordilheira. Entremeiam essas Serras e Chapadas, corredores rebaixados e praticamente planos, posicionados em níveis altimétricos ao redor dos 400/500m, definindo Depressões Intermontanas que se articula para norte ao longo da bacia hidrográfica do rio Tocantins e Depressão do Tocantins.

As terras elevadas são mantidas por sequencias de anticlinais e sinclinais fortemente erodidas. Esses testemunhos dos antigos dobramentos têm nas bordas, cristas assimétricas de quartzitos e o interior das anticlinais escavadas presença de formas em morros com topos convexos amplos e sustentados por granitos Estes granitos correspondem às massas ígneas intrusivas subjacentes, cujos processos erosivos com sucessivos rebaixamentos ao longo de milhões de anos; os exumaram. As terras mais baixas e aplanadas, que configuram as depressões intermontanas, são dominantemente esculpidas em rochas metamórficas menos resistentes, como os micaxistos, filitos e outras.

A maior parte dos soerguimentos/arqueamentos identificados no território brasileiro está vinculada a setores dos Cinturões Orogenéticos antigos. Assim se dá com os arqueamentos no Rio Grande do SulUruguai, no arco de Ponta Grossa, na flexura de Goiânia, no arco de São Vicente (MT), no arqueamento do Nordeste Oriental (Borborema), no Espinhaço/Quadrilátero Ferrífero, na faixa mais próxima da costa do Cinturão do Atlântico nas serras do Mar, Mantiqueira, Bocaina, Orgãos, Caparaó entre outras. Essas áreas têm em sua gênese o histórico da atividade tectônica, desde o momento que surgiram como estruturas dobradas, metamorfizadas e magmatizadas. É de se esperar, portanto, que essas áreas se constituam nas mais sensíveis aos eventos geotectônicos mais recentes em função de sua história genética.

No cinturão orogenético do Atlântico os processos geológicos na formação das faixas de dobramentos do Proterozóico, têm um histórico pré-abertura do Atlântico, e nos remete aos amplos e diversificados processos erosivos ocorridos no fim do Proterozóico e ao longo do Paleo, Meso e Cenozóico, que rebaixaram as cadeias montanhosas e construíram superfícies aplanadas descontínuas, irregulares e desniveladas pelas fases tectônicas meso-Cenozóicas. A faixa do Cinturão do Atlântico, sobretudo na região Sudeste é muito marcada pela tectônica Cenozóica. Gontijo (1999), em estudo acerca da morfotectônica do médio Paraíba do Sul, fez importante revisão sobre as informações geotectônicas para os terrenos do Cinturão Orogenético do Atlântico. Entre as informações resgatadas está a interpretação de Saadi (1993) que correlaciona os pulsos andinos identificados por Frutos (1981) aos eventos neotectônicos brasileiros.

Hasui et al. (1998), enfatizam que no sudeste brasileiro como decorrência da separação dos continentes sul-americano e africano (?) no Mesozóico, resultou em soerguimento regional do Mesozóico ao Paleogeno (Terciário Inferior), seguido de grandes desnivelamentos de blocos através de falhas responsáveis pela individualização das serras ancestrais do Mar e Mantiqueira e pela geração dos grábens Terciários, havendo no Neogeno-Quaternário (Plioceno e Pleistoceno) a compartimentação da região em grandes domínios morfológicos.

As atividades tectônicas que atuaram no continente sul-americano, a partir do Jurássico e ao longo do Cretáceo e Cenozóico, com prevalência no Terciário, foram responsáveis pelos processos geradores dos rifts marcados por falhamentos transcorrentes, escarpamentos, geração de grábens/horsts e formação nessas depressões tectônicas de bacias sedimentares sintectônicas, ou seja, de formação concomitante à atividade tectônica. Estes processos tanto ocorreram nas terras emersas como na plataforma continental e talude, sobretudo na faixa atlântica desde o litoral Sul até o Nordeste Oriental. São exemplos representativos as bacias sedimentares nas terras emersas ou, das também denominadas, bacias continentais trafogenéticas, como as bacias cenozóicass de São Paulo, Taubaté, Rezende, Curitiba, Pariquera-Açu, Volta Redonda, Guanabara, Itaboraí, geradas, conforme Ricomini (1989), a partir do Oligoceno-Mioceno.

Desde os trabalhos de Ricomini (1989/1991), reafirmadas por Gontijo (1999), tem-se informações claramente demonstradas que essas atividades tectogenéticas continuam ativas após a formação dos depósitos sedimentares, quando esse autor identificou deformações nos sedimentos das bacias continentais de Rezende e que se proliferam nos depósitos das bacias sedimentares vizinhas, conforme se pode, com certa 
frequência, observar em cortes sobre as colinas da bacia sedimentar de Taubaté. Corrobora esta análise, os resultados sismográficos parciais apresentados por Assumpção et al. (2015), sobre os dados de 2013 e 2014 gerados pela Rede Sismográfica Brasileira. O pequeno mapa síntese que ilustra a referida publicação, mostra claramente alguns eixos ou áreas onde a frequência de abalos sísmicos é maior no território brasileiro, sendo bastante evidente a concentração na faixa atlântica, com destaque a região Sudeste e a faixa que adentra para o centro norte do país acompanhando os Cinturões Orogenéticos do Atlântico, Brasília e Paraguai-Araguaia.

\section{Morfoestruturas das Bacias Sedimentares Paleo-Mesozoicas.}

As morfoestruturas das bacias sedimentares paleo-mesozóicas estão representadas pelos Planaltos e Chapadas dos Parecis, Planalto da Amazônia Oriental, Planaltos e Chapadas da Bacia do Parnaíba e Planaltos e Chapadas da Bacia do Paraná bem como as Depressões Periféricas da Borda Leste da Bacia do Paraná, a Depressão Central Gaúcha e as Depressões Monoclinais e Patamares estruturais que ocorrem nas extremidades norte e oeste desta bacia nos Estados de Goiás, Mato Grosso e Mato Grosso do Sul.

A Chapada dos Parecis, que corresponde à área mais elevada do Planalto dos Parecis está nivelada nos $800 \mathrm{~m}$, altitude semelhante à borda da Bacia do Paraná, representada pela Chapada dos Guimarães, cujos topos também são mantidos pelos arenitos do Cretáceo. Ross (2014) reinterpretando a morfogênese da Chapada dos Guimarães (MT), posicionada na borda norte da Bacia do Paraná e praticamente contínua à Chapada dos Parecis, que se posiciona à noroeste desta, sintetiza que:

[...] a Chapada dos Guimarães é produto da combinação de processos geotectônicos desencadeando movimentação crustal em razão da abertura do Atlântico, orogenia Andina e soerguimentos generalizados da plataforma sul-americana a partir do Jura-cretáceo, e estendendo-se por todo o Cenozóico, somados aos arqueamentos dômicos ao longo dos grandes alinhamentos estruturais, como o que ocorre na faixa de dobramentos Paraguai-Araguaia, denominado de Arco de São Vicente. (ROSS, 2014, p. 195)

Ross (2014) considera que estas chapadas e as depressões que as circundam, tanto ao sul quanto ao norte e oeste, foram geradas ao longo de mais de 65 Ma e não como suponha Ab’Saber (1972), que considerava como sendo decorrentes dos processos denudacionais do Plio-Pleistoceno, ou seja, do rebaixamento erosivo produzido apenas por três ou quatro milhões de anos.

As morfoestruturas, que sustentam os Planaltos e Chapadas das Bacias Sedimentares do Paraná, do Parnaíba, da Amazônia Oriental, e dos Parecis, têm em comum o fato de estarem em posições altimétricas mais elevadas do que no momento em que foram geradas e compostas por sedimentos de origem continental datados do Cretáceo. Com exceção da bacia do Parecis, cujos depósitos são exclusivamente do Cretáceo, as demais têm em suas formações geológicas sedimentos de várias origens (marinhos, continentais, glaciais), com idades que vão desde o Paleozóico (Devoniano, Siluriano, Carbonífero, Permiano) chegando ao Mesozóico, com sedimentos eólicos de ambientes áridos (Triássico), vulcânicas ácidas e básicas (TriássicoJurássico) e depósitos continentais de arenitos em setores na época mais embaciados (Cretáceo).

O que desperta a atenção são de fato os soerguimentos, arqueamentos e sinéclises que estas bacias sofreram em todas as suas extensões, mas principalmente em suas bordas. Essa epirogênese é considerada como Pós-Cretácea pelo fato de ter colocado os arenitos desta idade em posições altimétricas muito variadas, mas que chegam a 800/850m na Chapada dos Parecis, a 900/1.000m nas bordas mais proeminentes da bacia do Paraná, na Chapada dos Guimarães, no Planalto Residual de Franca e de São Carlos-Botucatu, em São Paulo, e acima de 900m na Chapada do Ibiapaba, no Ceará-Piauí, na bacia do Parnaíba, ou em altitudes mais modestas nas bordas norte e sul da bacia da Amazônia Oriental, onde atinge no máximo 400m, no Planalto da Amazônia Oriental.

As bordas desses Planaltos e Chapadas são delimitadas por escarpas cujos processos erosivos, Cenozóicos, foram induzidos pela tectônica, que ao promover a epirogenia gerou falhamentos, a partir dos quais as atividades erosivas passaram a atuar. Esses processos tectônicos e erosivos certamente não ocorreram de forma brusca e única, mas ao longo de mais de 65 milhões de anos (Cenozóico) e de modo concomitante, ou seja, ao mesmo tempo em que se processavam os esforços e a atuação tectônica, as erosões se instalaram e evoluíram na direção de gerar os Planaltos e Chapadas, nas bordas das bacias, e um amplo e generalizado rebaixamento morfológico, correspondentes às depressões. As análises geomorfológicas, apresentadas por diversos autores, sinalizam na direção de que a abertura dessas superfícies rebaixadas, que deram origem às Depressões Periféricas e Marginais (AB’SABER, 1949, 1972) que circundam parcialmente as grandes bacias sedimentares foi esculpida por fases de maiores ou menores atividades tectônicas 
acompanhadas de variado vigor erosivo, com condições de alternâncias climáticas secas, coincidentes com prolongados períodos glaciais e menor oferta de água líquida no sistema atmosférico e nos interglaciais climas mais quentes e úmidos e maior disponibilidade de água no estado líquido. Essas depressões circundantes às bacias sedimentares (periféricas, monoclinais e marginais) são, portanto, produtos da combinação dos processos tectônicos Cenozóicos identificados por soerguimentos e falhamentos, e de processos erosivos promovidos por diferentes condições climáticas. Há consenso de que os soerguimentos se dão de forma mais ou menos intermitentes, ou seja, ainda que as atividades tectônicas nunca cessem, suas intensidades oscilam no tempo e no espaço.

\section{Morfoestrutura do Cinturão Orogenético dos Andes e Bacias Cenozoicas.}

A Cordilheira dos Andes, que se estende de norte a sul em paralelo e entre a Depressão Central, a leste, e o Oceano Pacifico, a oeste, é uma decorrência dos processos da deriva dos continentes e, portanto, das associadas à movimentação das placas litosféricas da América do Sul tal como a de Nazca e do Pacífico que estão sob as águas do oceano. A submersão ou subducção das placas de Nazca e do Pacífico (sul), sob a placa Sul-americana, é o mecanismo que explica a dominância dos processos geotectônicos que ocorrem em todo o continente e fornece as pistas para a interpretação da evolução do relevo no território brasileiro. Zalan (2004), ao sintetizar dados produzidos por diversos autores sobre a orogenia andina, indica que o processo de formação da Cordilheira Andina se deu por fases de dobramentos que se iniciam no Cretáceo Médio (96/106 milhões de anos), denominada de fase Mochica, pré-Andina. A essa fase inicial de dobramentos acrescentam-se outras, como a fase Peruana Cretáceo, pouco mais recente, da ordem de 83 a 87 milhões de anos; a fase Cordilheira Ocidental, também do Cretáceo Superior, com tempo da ordem de 65 a 74 milhões de anos. No Cenozóico, outras duas fases orogenéticas são identificadas: a fase Incaica do CenozóicoEoceno, com 33 a 53 milhões de anos, e a fase Quechua-Cenozóico-Mioceno/Plioceno, entre 1,7 a 23 milhões de anos.

A fase Mochica, do Cretáceo Médio, se articula com a existência da Cordilheira Andina Oriental e com o denominado Altiplano Boliviano, com topos posicionados acima de 4.000 metros de altitude. As fases Cordilheira Ocidental, do Cretáceo Superior, e a Incaica, do Cenozóico Médio (Eoceno), associam-se a toda extensão do eixo central da Cordilheira Andina, desde o extremo sul do Chile à Colômbia e à Venezuela, cujas altitudes oscilam em $2.600 \mathrm{~m}$ para estruturas sedimentares dobradas ou com extensas áreas soerguidas e niveladas, constituindo amplos patamares aplanados em determinados setores da cordilheira.

Para as faixas de vulcanismo, as altitudes chegam a mais de $4.000 \mathrm{~m}$ e acompanham linearmente todo o centro (de norte a sul) da cordilheira. A fase Quechua do Terciário Médio ao Superior (Mioceno/Plioceno) refere-se à última fase de dobramentos que atingem a Cordilheira da Costa, que é preferencialmente composta por sedimentos terciários dobrados e secundariamente derrames vulcânicos.

A cordilheira da Costa ou Costeira tem altitudes que oscilam em torno dos $1.500 \mathrm{~m}$ e é acompanhada, no interior, de forma também descontínua, por depressões paralelas, alongadas e dominantemente planas, com altitudes, em geral, 500m mais baixas. Observa-se, entretanto, que no Chile essas depressões internas, que possivelmente representam grandes vales sinclinais, perdem altitude de norte para o sul. Enquanto no extremo norte do Chile, um segmento dessas depressões, na região da cidade de Calama, tem altitudes por volta dos $1.400 \mathrm{~m}$. Este amplo vale interior projeta-se para noroeste na faixa próxima a costa do sul do Peru (Província de Arequipa) como um grande patamar estrutural dominantemente plano e escarpado em seus limites oeste com altitudes entre 1500 a 2000m, denominado regionalmente como Pampa de Mages (ROSS e SOUSA, 2018). Mais para o sul, onde se encontra a metrópole de Santiago, as altitudes estão ao redor dos 700/800m, e, no extremo sul do país, uma dessas depressões encontra-se afogada pelas águas oceânicas, oferecendo um litoral extremamente recortado e entremeado por serras, morros, vulcões e mares interiores.

No contexto geral, os setores mais elevados regionalmente correspondem à faixa do sul do Peru e do norte do Chile, em direção leste para o território da Bolívia, onde prevalecem as terras mais altas da Cordilheira Andina Oriental. É nessa faixa que se encontram, sobre os Andes, as nascentes do rio Pilcomayo, que drena para o rio Paraguai, e dos rios Beni e Mamoré, que drenam para o rio Madeira e, portanto, para a bacia Amazônica.

A Cordilheira Andina e a Depressão Central Sul-americana são partes de um mesmo contexto geotectônico. A Depressão Central Sul-americana se estende desde a Venezuela, onde está instalada a bacia hidrográfica do rio Orinoco, abrangendo o alto Solimões, na Amazônia Ocidental, a alta bacia dos rios BeniMamoré-Guaporé, as bacias do rio Paraguai e do baixo rio Paraná-Prata. Constitui-se por relevo de altitudes modestas, cujos valores mais altos estão a 250m, no interflúvio das bacias dos rios Beni-Mamoré e Paraguai, em território boliviano. Em sua extensão norte-sul, pelo centro do continente sul-americano, há áreas 
constituídas por Planícies e Pantanais como ocorre com parte da média e alta bacia do rio Orinoco, onde estão as Savanas do mesmo nome, ou na alta bacia dos rios Beni-Mamoré, onde estão os Chacos, com campos, e os Pantanais, como os do Guaporé, no Brasil, ou ainda as Planícies e Chacos/Pantanais, do rio Paraguai, onde se inclui o Pantanal de Mato Grosso e os Chacos da Bolívia e Paraguai.(ROSS, 2016).

O relevo correspondente aos níveis de terraços marinhos e tabuleiros, encontrados descontinuamente tanto no litoral do Pacífico, como no litoral norte/nordeste e leste do Brasil, correspondendo aos sedimentos da Formação Barreiras, datada do Terciário Superior (Mioceno/Plioceno), pode ser explicado por dois mecanismos, o tectônico e as oscilações dos níveis marinhos. Entretanto, a existência de espessos pacotes sedimentares compondo terraços fluviais com 20 a 50 metros de espessura com significantes incisões dos vales, acompanhados de recuos de cabeceiras, capturas fluviais generalizadas e intensa dissecação do modelado no interior do continente junto aos planaltos e montanhas, não podem ser explicados por movimentos dos níveis marinhos, ou somente por alternâncias climáticas seco-úmido. Considera-se que estas evidências, reforçam a interpretação de que além das várias fases úmidas, também foram acompanhadas por atividade tectônica atual (Pleistoceno/Holoceno) influenciando na modelagem das formas menores.

\section{Algumas Reflexões Finais}

As questões relativas aos efeitos climáticos atuais e paleoclimáticos no contexto dos processos esculturais do relevo da América do Sul não foram objeto de caracterização e análise neste trabalho que tem um viés cartográfico de representação de grandes formas do relevo, onde os arranjos das macroestruturas geológicas condicionam a morfologia dominante. No contexto da escala de trabalho e de publicação, este mapa das macroformas do relevo da América do Sul evoluiu de um trabalho anterior publicado na Revista Brasileira de Geografia do IBGE sob a denominação "O Relevo Brasileiro no Contexto da América do Sul", ocasião em que este mapa foi apresentado como uma figura para a ilustração. Após essa primeira publicação sobre o tema foram feitas outras três viagens exploratórias de campo pela cordilheira Andina e Planalto da Patagônia, que nos permitiu promover alguns ajustes de limites e de denominação das unidades de relevo, mantendo-se, em função da escala os dois primeiros táxons de acordo com a metodologia de Ross (1992). Manteve-se, portanto, a representação das macro_formas tendo como primeiro táxon as morfoestruturas e em cada uma destas, o segundo táxon com suas respectivas morfoesculturas.

As morfoestruturas revelam as condições geológicas na perspectiva estrutural, genética e cronológica das formações rochosas, que dão suporte às unidades morfoesculturais produzidas pelo desgaste erosivo da diversidade climática que atuou e atua ao longo do tempo e do espaço ora representado. Há entendimento nas pesquisas geomorfológicas que as variações, oscilações e as mudanças climáticas, sobretudo, no Cenozóico através de condições alternadas entre climas áridos, semiáridos, frios, quentes e úmidos, com mudanças globais entre períodos glaciais e interglaciais, modelam ou esculpem as bases geológicas das morfoestruturas e geram os arranjos superficiais do modelado. Esses processos esculturais promovem denudações que se revelam como rebaixamentos erosivos e fornecem diferentes fisionomias morfológicas que guardam familiaridade genética entre si no contexto de cada morfoestrutura.

Cada tipologia de morfoestrutura revela resultados morfológicos diferenciados face aos tipos de materiais e aos diferentes processos climáticos atuantes sobre as mesmas. Deste modo, a morfogênese e a pedogênese vão sendo desenvolvidas e retrabalhadas permanentemente diante de novos eventos tectônicos e permanente atividade climática. $\mathrm{O}$ entendimento de cada uma das unidades de relevo por meio das pesquisas sistemáticas em diferentes escalas vai revelando os "segredos da natureza" que estão escondidos nas paisagens geomorfológicas, possibilitando a originalidade da história morfogenética de cada lugar do planeta.

\section{Referências}

AB `SABER, A. N. Regiões de Circundesnudação Pós-Cretáceos no Planalto Brasileiro. Boletim Paulista de Geografia. São Paulo, v.1, p.1-21, 1949.

AB`SABER, A. N. Participação das Depressão e Superfícies Aplainadas na Compartimentação do Planalto Brasileiro. Geomorfologia. IGEOG - USP. São Paulo, v.28, 20p., 1972.

AB`SABER, A. N. Megageomorfologia do Território Brasileiro. In: CUNHA, S. B.; GUERRA, A. J. T. (org.). Geomorfologia do Brasil. Rio de Janeiro: Editora Bertrand-Brasil, p.71-106, 1998.

ASSUMPÇÃO, M.; BARBOSA, J. R.; BIANCHI, M.; DROUET, S.; ROCHA, M. P.; FERREIRA, J. M. Sismos Regionais Detectados pela Rede Sismográfica Brasileira - RSBR em 2013-2014. In: XV Simpósio Nacional de Estudos Tectônicos. Vitória, ES, 2015. 
CHANG, H. K.; KOWSMANN, R. O.; FIGUEIREDO, A. M. F. Novos Conceitos sobre os Desenvolvimentos das Bacias Marginais do Leste Brasileiro, In Raja Gabaglia, G.P.; Milani, E.J.;-Origem e Evolução de Bacias Sedimentares- Petrobras- p.269-289- Rio de Janeiro-1992. .

COX, R. T. The Role of Mantle Plumes in the Development of Continental Drainage Patterns. Nature. N..York, v.342, p.21-28, 1989.

ENGELN, O. D. von. Geomorphic Units. New York: Ed. Macmillan. 1942.

FONSECA, G. P. S. Formas de Relevo e os Materiais de Superfície do Pantanal de Poconé-MT. Tese de doutorado apresentada à FFLCH/USP, São Paulo, 282 p 2015.

FRUTOS, J. Andean Tectonicas a Consequence of Sea-floor spreading. Tectonophycs. N.York, v.72, p.21-32, 1981.

GONTIJO, A. H. F. Morfotectônica do Médio Vale do Rio Paraíba do Sul: Região da Serra da Bocaina Estados de SP-RJ. 1999p 306p. Tese de doutorado apresentada no Instituto de Geociências e Ciências Exatas/UNESP, Rio Claro - SP, 1999.

HASUI, Y.; COSTA, J. B. S.; BORGES, M. S., MORALES, N.; RUEDA, J. R. J.;- Evolução Morfotectônica do Sudeste do Brasil, in SBG-Anais do Congresso Brasileiro de Geologia- 40 p 78/79 Belo Horizonte,. (1998).

LADEIRA, F. S. B.; SANTOS, M. Tectonic and Cenozoiic Paleosols in Itaqueri's Hill (São PauloBrazil): Implications for the Long Term Geomorphological Evolution. Z. Geomorphology N.F Suppl. Berlin-Stuttgart, v.145, p.37-62, 2006.

MESCERJAKOV, J. P. Les Concepts de Morphostruture et de Morphosculture: un nouvel instrument de l'analyse géomorphologique. Annales de Geographie. v.423, p.539-552, 1968.

ROSS, J. L. S. O Relevo Brasileiro no Contexto da América do Sul, Ver. Bras. Geografia,Rio de Janeiro, v.61 n.1 p.21-58, 2016

ROSS, J. L. S. O Relevo Brasileiro nas Macroestruturas Antigas. Revista Continentes. Rio de Janeiro, UFRRJ, Ano 1, v.2 p.8-27, Rio de Janeiro,2013.

ROSS, J. L. S. Chapada dos Guimarães: Borda da Bacia do Paraná. Revista Depto.Geografia. , FFLCHUSP, v.28, p.180-197, São Paulo 2014.

ROSS, J. L. S. Estudo e cartografia geomorfológica da Província Serrana. MT. Tese de Doutorado apresentada à FFLCH/USP, São Paulo, 1987.

ROSS, J. L. S. Relevo Brasileiro: Uma nova proposta de classificação. Revista do Departamento de Geografia., v.4, FFLCH/USP, p.25-39, São Paulo, 1990.

ROSS, J. L. S. O Relevo Brasileiro, as Superfícies de aplainamento e os Níveis Morfológicos. Revista do Departamento de Geografia., v.5, FFLCH/USP, p.7-24, São Paulo, 1991.

ROSS, J. L. S. O Contexto Geotectônico e a Morfogênese da Província Serrana de Mato Grosso. Revista I.G., v.12(1/2), p.21-37, São Paulo, 1991.

ROSS, J. L. S. Geomorfologia e Geografia Aplicadas à Gestão Territorial: Teoria e Metodologia para o Planejamento Ambiental. . 322p, 2001. Tese de Livre Docência apresentada à FFLCH/USP, São Paulo, 2001.

ROSS, J. L. S. A Morfogênese da Bacia do Ribeira do Iguape e os Sistemas Ambientais. Revista GEOUSP. , v.12, p.21-46, São Paulo 2002.

ROSS, J. L. S; SOUSA, A. S. A Morfodinâmica no Deserto Andino: Bacia do Rio Siguas-Peru-Anais do XII-SINAGEO- UGB- Crato-CE, 2018

ROSS, J. L. S.; MOROZ, I. C. Mapa Geomorfológico do Estado de São Paulo - escala 1:500.000. FFLCH-USP-IPT-FAPESP, 64p., São Paulo 1997.

SAADI, A. Neotectônica da Plataforma Brasileira: esboço e interpretações preliminares. Revista Geonomos, v.1, p.1-15, Belo Horizonte, 1993.

ZALAN, P. V. Evolução Fanerozoica das Bacias Sedimentares Brasileiras. In: Geologia do Continente Sul-americano: Evolução da obra de F. F. M.de Almeida. São Paulo: Editora Beca, p.595-613, 2004. 